\title{
Accuracy of thermistors and thermocouples as flow-measuring devices for detecting hypopnoeas
}

\author{
R. Farré*, J.M. Montserrat**, M. Rotger*, E. Ballester**, D. Navajas*
}

\begin{abstract}
Accuracy of thermistors and thermocouples as flow-measuring devices for detecting hypopnoeas. R. Farré, J.M. Montserrat, M. Rotger, E. Ballester, D. Navajas. OERS Journals Ltd 1998.

ABSTRACT: The aim of this work was to assess the accuracy of thermistors/thermocouples as devices for detecting hypopnoeas in sleep studies.

Conventional thermistor/thermocouples were studied with a respiratory model allowing the simulation of inspiratory $\left(22^{\circ} \mathrm{C}\right)$ and expiratory $\left(37^{\circ} \mathrm{C}\right)$ flows. The thermistor signal $\left(V^{\prime}\right.$ th) was compared with a pneumotachograph $\left(V^{\prime}\right)$ : 1) for sinusoidal

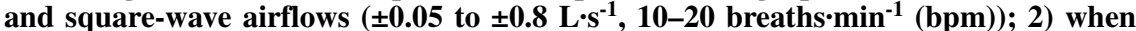
changing the distance from the thermistor to the nose $(0-20 \mathrm{~mm})$; and 3) when doubling the section of the nostrils.

The thermistor was strongly nonlinear and flow reductions (hypopnoeas) were underestimated: a $50 \%$ reduction in $V^{\prime}\left( \pm 0.5 \mathrm{~L} \cdot \mathrm{s}^{-1}, 15 \mathrm{bpm}\right.$, sinusoidal) resulted in only an $18 \%$ reduction in $V^{\prime}$ th. $V^{\prime}$ th depended considerably on the airflow pattern: for $V^{\prime}= \pm 0.5 \mathrm{~L} \cdot \mathrm{s}^{-1}, V^{\prime}$ th increased by $100 \%$ from sinusoidal $(20 \mathrm{bpm})$ to square-wave $(10$ bpm). For $V^{\prime}= \pm 0.5 \mathrm{~L} \cdot \mathrm{s}^{-1}, 15 \mathrm{bpm}$, sinusoidal flow, $V^{\prime}$ th increased by $79 \%$ when the distance thermistor-nose varied from $20-0 \mathrm{~mm}$, and $V^{\prime}$ th decreased by $37 \%$ when doubling the nose section.

We concluded that thermistor/thermocouples are inaccurate flow-measuring devices when used at the airflow conditions typical of sleep studies. Their use for quantifying hypopnoeas may lead to considerable underdetection of these respiratory events. Eur Respir J 1998; 11: 179-182.
\end{abstract}

*Lab. Biofisica i Bioenginyeria, Facultat de Medicina, Universitat de Barcelona. **Servei de Pneumologia, Hospital Clinic Provincial de Barcelona, Spain.

Correspondence: R. Farré

Lab. Biofisica i Bioenginyeria

Facultat de Medicina

Casanova 143

E-08036 Barcelona

Spain

003434035260

Keywords: Airflow measurement hypopnoea

monitoring

pneumotachograph

sleep apnoea syndrome

thermally sensitive devices

Received: June 301997

Accepted after revision October 281997

This work was supported in part by $\mathrm{Co}$ misión Interministerial de Ciencia y Tecnología (CICYT, SAF96-0076).
Breathing airflow is a physiological variable commonly monitored for assessing respiratory patterns and nocturnal events in studies aimed at diagnosing sleep disorders [1-3]. Given that in sleep studies the use of a pneumotachograph, which is the reference transducer for measuring flow, is rather cumbersome, airflow is routinely assessed by means of thermally sensitive devices such as thermistors and thermocouples. The main advantage of these devices is that they are small and light and, consequently, their use causes a minimum amount of disturbance to the patient during sleep. However, thermistors and thermocouples are semiquantitative devices since the flow signal they provide is not a direct measure of actual flow [4-6]. This drawback, which does not pose major problems for detecting apnoeas, is however relevant to scoring hypopnoeas $[7,8]$, given that the definition of these events is made in terms of quantitative reduction in airflow.

Precise characterization of the performance of thermistor/thermocouples when used for measuring airflow in sleep studies requires a laboratory study under controlled conditions. Indeed, contrary to what happens when testing linear transducers, the analysis of a slow-response nonlinear system such as a thermistor/thermocouple [6] requires subjecting it to a variety of input airflows covering the ranges of amplitudes, frequencies and waveforms found in the particular application. Such a systematic study cannot be carried out in patients during sleep since it is not possible to modify the pattern of the breathing airflow in a selective and controlled way. Moreover, pneumo-tachographs, which may modify the thermal conditions in the thermistor/thermocouple, or thoracoabdominal bands, which may not be adequate during padoxical breathing, are not perfect reference flow transducers in this application. The aim of this study was to characterize the accuracy of thermistor/thermocouples as flow-measuring devices for detecting hypopnoeas. To this end, we set up a respiratory model to reproduce the measuring conditions of nasal airflow by means of thermally sensitive devices.

\section{Materials and methods}

The response of thermistors and thermocouples was studied with the respiratory system model shown in figure 1. The model was based on a $60 \mathrm{~L}$ methacrylate chamber which was used as a buffer of heated air at $37^{\circ} \mathrm{C}$. The air temperature in the chamber was measured with a mercury-bulb thermometer and was maintained $\left( \pm 0.2^{\circ} \mathrm{C}\right)$ by means of a $120 \mathrm{~W}$ heating resistance supplied with the required voltage. Homogeneous distribution of air temperature in the chamber was achieved by means of mixing airflow generated by an internal fan. A flow generator based on a servocontrolled linear motor attached to rubber bellows [9, 10] was connected to the rear wall of the chamber. The linear motor allowed us to generate any 


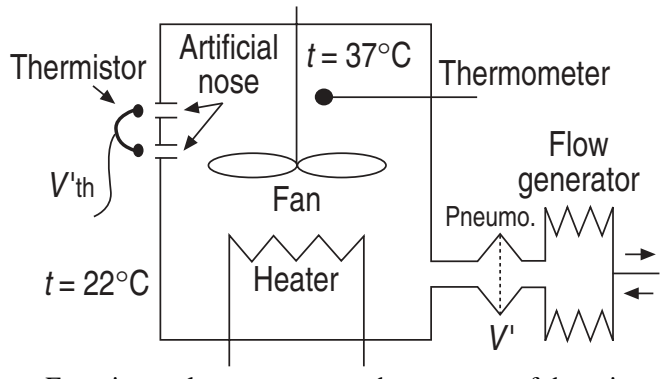

Fig. 1. - Experimental setup to assess the response of thermistors/thermocouples as flow-measuring devices. A heater and a fan maintain a homogeneous and constant temperature $(t)$ of the air in the chamber. A flow generator drives inspiratory $\left(22^{\circ} \mathrm{C}\right)$ and expiratory $\left(37^{\circ} \mathrm{C}\right)$ flows through the artificial nose. The actual flow $\left(V^{\prime}\right)$ measured by a pneumotachograph (Pneumo.) is recorded by the thermistor/thermocouple signal ( $V^{\prime}$ th).

pattern of airflow because its motion was servocontrolled by means of the flow signal $\left(V^{\prime}\right)$ recorded with a Fleisch II pneumotachograph (Metabo, Epalinges, Switzerland) and a differential pressure transducer (MP-45, $2 \mathrm{hPa}$, Valydine, Northridge, CA, USA) placed between the bellows and the chamber. An artificial nose was built in the front wall of the chamber. It consisted of two cylindrical tubes, $6 \mathrm{~mm}$ in diameter and $30 \mathrm{~mm}$ in length, with their centres placed at a distance of $20 \mathrm{~mm}$.

Two identical thermistors (Sleeplab 1000P, Aequitron, Minnesota, MN, USA) and two identical thermocouples (ONT2; Grass Instrument Company, Quincy, MA, USA) of common use in sleep studies were tested. The thermally sensing probes corresponding to the nostrils were placed in front of the orifices of the artificial nose at a distance of $10 \mathrm{~mm}$. The signal from the thermistor/thermocouple ( $V^{\prime}$ th) and the actual flow $V^{\prime}$ were band-pass filtered (Butterworth, 8 poles, $0.05-32 \mathrm{~Hz}$ ). The gains of the thermistor and of the thermocouple signals were fixed so as to obtain an amplitude $V^{\prime}$ th $= \pm 0.5 \mathrm{~V}$ when these devices were subjected to a sinusoidal flow with a frequency of 15 breaths $\cdot \mathrm{min}^{-1}(\mathrm{bpm})$ and with an amplitude of $\pm 0.5 \mathrm{~L} \cdot \mathrm{s}^{-1}$. These values of frequency and amplitude were taken as reference values since they are representative of normal spontaneous breathing. The response of the thermistor/ thermocouple was analysed by comparing the signal $V^{\prime}$ th with the $V^{\prime}$ recorded simultaneously by the pneumotachograph. All the measurements were repeated three times and the average value was taken.

To avoid interference with the thermally sensitive device the thermistor/thermocouple was compared with a reference pneumotachograph which was connected to the rear wall of the chamber. Given the frequencies investigated, estimating airflow through the artificial nose by means of the pneumotachograph was expected to be negligibly affected by the gas compression in the chamber. Indeed, given the airflow resistance of the nostrils and the compliance of air in the chamber, the air shunt was characterized by a time constant of $\sim 50 \mathrm{~ms}$. Consequently, at the highest investigated frequencies $(20 \mathrm{bpm}=0.33 \mathrm{~Hz})$ the airflow amplitude at the nostrils was expected to be overestimated by $<1 \%$. These theoretical predictions were verified in a preliminary part of the study by adapting a second pneumotachograph at the external outlet of the nostrils. The difference in the flow amplitudes measured by both pneumotachographs was within the experimental variability.
The effect of the flow pattern on the response of one of the thermistors was analysed by selectively modifying the amplitude, the frequency and the airflow waveform. To this end, we carried out a series of measurements to determine the $V^{\prime}$ th- $V^{\prime}$ relationship when varying the amplitude of a sinusoidal flow $(15 \mathrm{bpm})$ from $\pm 0.05 \mathrm{~L} \cdot \mathrm{s}^{-1}$ to $\pm 0.8 \mathrm{~L} \cdot \mathrm{s}^{-1}$. To test the effect of the respiratory frequency on the $V^{\prime}$ th- $V^{\prime}$ relationship of the thermistor we also investigated the amplitude dependence when the frequency of the sinusoidal flow was $10 \mathrm{bpm}$ and $20 \mathrm{bpm}$. To check the influence of the airflow waveform we investigated the $V^{\prime}$ th- $V^{\prime}$ relationship by generating square-wave flows of different amplitudes (from \pm 0.05 to $\pm 0.5 \mathrm{~L} \cdot \mathrm{s}^{-1}$ ) at frequencies of 10,15 and $20 \mathrm{bpm}$.

The dependence of the response of one of the thermistors on the distance from the device to the nostrils and on the section of the artificial nostrils was also investigated for sinusoidal flows of $15 \mathrm{bpm}$ and amplitudes from \pm 0.05 to $\pm 0.5 \mathrm{~L} \cdot \mathrm{s}^{-1}$. The relationship $V^{\prime}$ th- $V^{\prime}$ was assessed when the thermistor-nose distance was varied from $10 \mathrm{~mm}$ to 0 $\mathrm{mm}$ and to $20 \mathrm{~mm}$. The influence of the section of the artificial nostrils was investigated by modifying the internal diameter of the tubes in the artificial nose from $6 \mathrm{~mm}$ to $8.5 \mathrm{~mm}$ (100\% increase in section).

\section{Results}

The thermistor was not able to accurately measure the actual flow, as illustrated by the examples in figure 2. Figure 2 a shows sections of the actual $V^{\prime}$ : sinusoidal with 1 $\mathrm{L} \cdot \mathrm{s}^{-1}$ peak-to-peak (left); sinusoidal with $0.5 \mathrm{~L} \cdot \mathrm{s}^{-1}$ peak-topeak (centre); and square-airflow with $0.5 \mathrm{~L} \cdot \mathrm{s}^{-1}$ peak-topeak (right). In all the cases the frequency was $15 \mathrm{bpm}$. Figure $2 \mathrm{~b}$ shows the corresponding $V^{\prime}$ th. The time-pattern of $V^{\prime}$ th was similar, regardless of the amplitude and waveform of the actual $V^{\prime}$. Comparison between the left and central panels shows that for the same waveform (sinusoidal) the actual reduction in flow was substantially underestimated by the thermistor. The central and right panels show that, for the same amplitude of actual $V^{\prime}$, the amplitude of the thermistor signal considerably depended on the airflow waveform. The amplitude of the thermistor signal for the sinusoidal flow on the left of the figure was almost the same as that corresponding to a square-wave airflow with $50 \%$ amplitude.
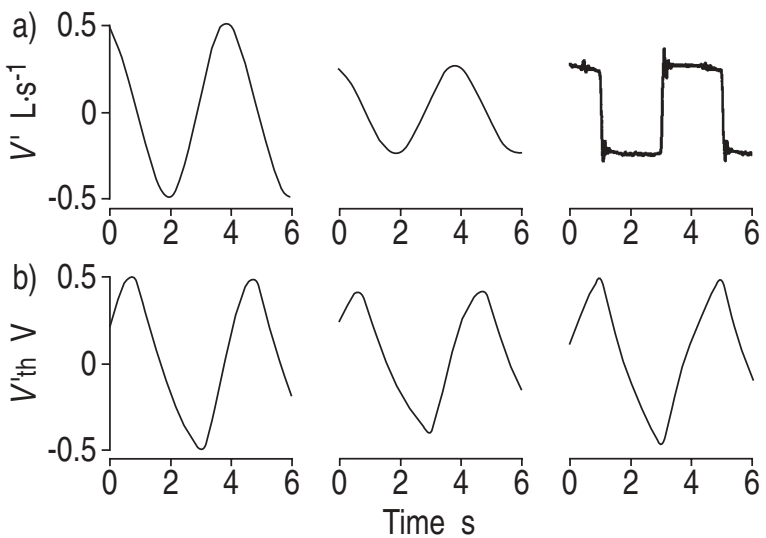

Fig. 2. - a) Actual flow measured by the pneumotachograph $\left(V^{\prime}\right)$ for sinusoidal airflows of $1 \mathrm{~L} \cdot \mathrm{s}^{-1}$ and $0.5 \mathrm{~L} \cdot \mathrm{s}^{-1}$ and for a square-wave flow of $0.5 \mathrm{~L} \cdot \mathrm{s}^{-1}$ (peak-to-peak). b) Thermistor signal $\left(V^{\prime}\right.$ th) recorded simultaneously. 


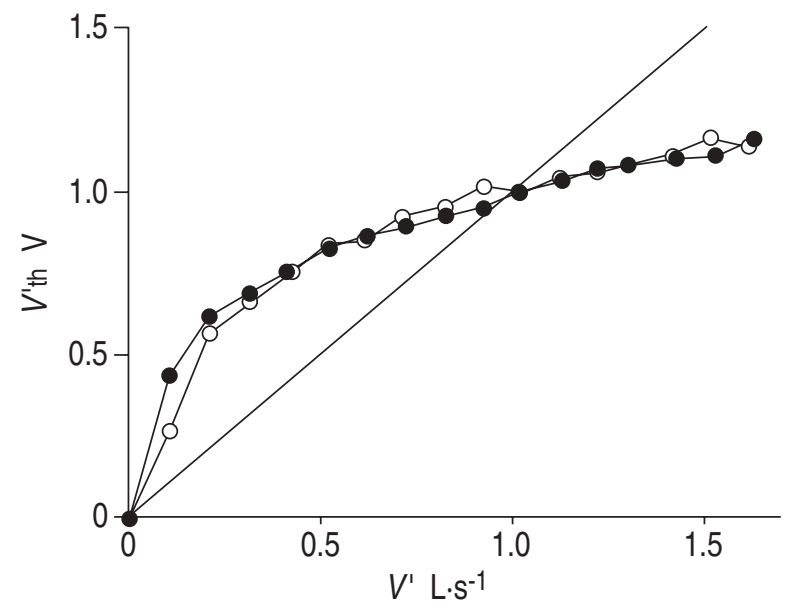

Fig. 3. - Relationship between the peak-to-peak amplitudes of the thermistor and the thermocouple signals ( $V^{\prime}$ th) and the actual flow amplitude $\left(V^{\prime}\right)$ for a sinusoidal flow of 15 breaths $\min ^{-1}$. $\bullet$ : thermistor; $\bigcirc$ : thermocouple.

Figure 3 shows the peak-to-peak amplitudes of the $V^{\prime}$ th of one of the thermistors and of one of the thermocouples as a function of the amplitude of the actual $V^{\prime}$ for a 15 bpm sinusoidal flow. Each data point corresponds to the average of three repeated measurements (mean coefficient of variation $\sim 5 \%$ ). Both of the thermally sensitive devices showed a very similar response. The relationship between $V^{\prime}$ th and $V^{\prime}$ was strongly nonlinear. For instance, a 50\% amplitude reduction in the actual $V^{\prime}$ (from a peak-to-peak of $1 \mathrm{~L} \cdot \mathrm{s}^{-1}$ to $0.5 \mathrm{~L} \cdot \mathrm{s}^{-1}$, which corresponds to the example in figure 2 left and centre) resulted in only an $18 \%$ amplitude reduction in the thermistor signal. The results obtained from the other thermistor and thermocouple were similar (within the experimental variability of $\sim 5 \%$ ) to those shown in figure 3 for the other identical sensors.

The effect of the frequency and waveform of airflow on the response of the thermistor is shown in figure 4. In addition to being nonlinear (out of the identity line), the relationship $V^{\prime}$ th- $V^{\prime}$ depended on the frequency to a considerable extent, both for sinusoidal and square-wave airflows. For a given waveform and amplitude of actual $V^{\prime}$, $V^{\prime}$ th increased as the frequency decreased. For a given amplitude of $V^{\prime}$ and frequency, the amplitude of $V^{\prime}$ th was

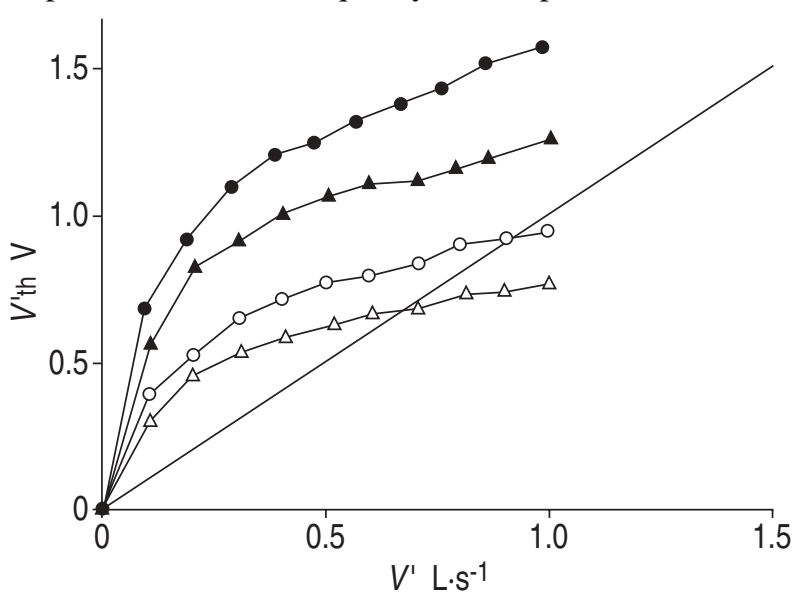

Fig. 4. - Relationship between the peak-to-peak amplitudes of the thermistor signal $\left(V^{\prime}\right.$ th) and of the actual flow $\left(V^{\prime}\right)$ for different frequencies (10 breaths $\left.\mathrm{min}^{-1}(\mathrm{bpm}), 20 \mathrm{bpm}\right)$ of sinusoidal (sin) and square-wave (sqr) airflows. $\bullet$ : sqr, $10 \mathrm{bpm}$; $\boldsymbol{\Delta}: \sin , 10 \mathrm{bpm}$; $\mathrm{O}: \mathrm{sqr}, 20 \mathrm{bpm} ; \Delta: \sin$, $20 \mathrm{bpm}$.

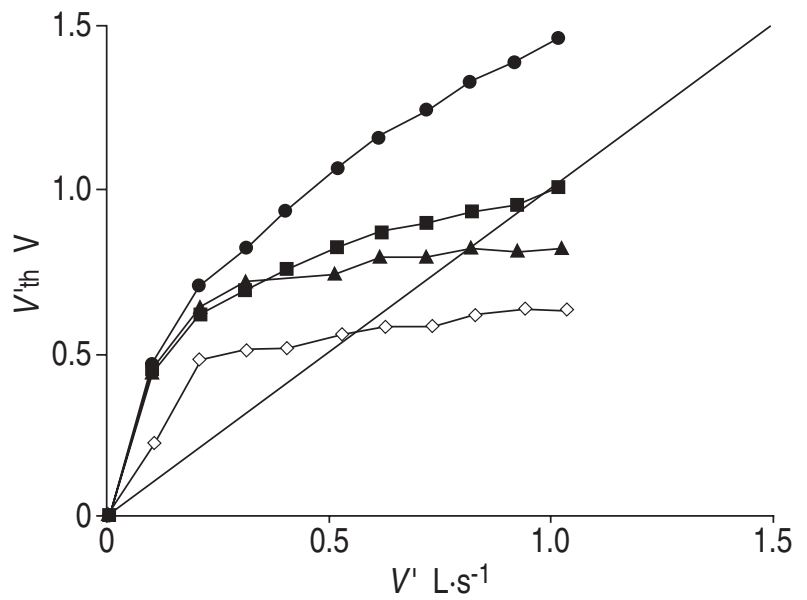

Fig. 5. - Relationship between the peak-to-peak amplitudes of the thermistor signal $\left(V^{\prime}\right.$ th $)$ and of the actual flow $\left(V^{\prime}\right)$ for different distances $(0$, $(\bullet), 10(\boldsymbol{\square}), 20(\boldsymbol{\Delta}) \mathrm{mm}$ ) between the thermistor and artificial nose and for a double section of the artificial nose $(\diamond)$ when the distance between the thermistor and the nose was $10 \mathrm{~mm}$.

greater for the square-wave airflow than for the sinusoidal airflow. For a sinusoidal flow of $1 \mathrm{~L} \cdot \mathrm{s}^{-1}$ peak-to-peak amplitude of actual $V^{\prime}$, the thermistor signal amplitude varied from $0.77 \mathrm{~V}$ at $20 \mathrm{bpm}$ to $1.26 \mathrm{~V}$ at $10 \mathrm{bpm}$, which corresponds to a $50 \%$ increase. The effect of frequency was even greater in case of square-wave airflow: from $0.95 \mathrm{~V}$ at $20 \mathrm{bpm}$ to $1.54 \mathrm{~V}$ at $10 \mathrm{bpm}(60 \%$ increase) for $V^{\prime}=1 \mathrm{~L} \cdot \mathrm{s}^{-1}$ (peak-to-peak amplitude).

As shown in figure 5, the thermistor signal showed a considerable dependence on the distance from the thermally sensitive probes to the artificial nose. Reducing this distance from 20 to $0 \mathrm{~mm}$ increased the thermistor signal. For $1 \mathrm{~L} \cdot \mathrm{s}^{-1}$ of peak-to-peak sinusoidal $(15 \mathrm{bpm})$ airflow, the amplitude of $V^{\prime}$ th varied from $0.82 \mathrm{~V}$ to $1.47 \mathrm{~V}$ (79\% increase). Moreover, figure 5 shows that, for any amplitude of $V^{\prime}$, doubling the section of the artificial nose resulted in a considerable decrease in the amplitude of the $V^{\prime}$ th: from $1 \mathrm{~V}$ to $0.63 \mathrm{~V}\left(37 \%\right.$ reduction) for $1 \mathrm{~L} \cdot \mathrm{s}^{-1}$ peakto-peak sinusoidal flow $(15 \mathrm{bpm})$ and a $10 \mathrm{~mm}$ distance between thermistor and artificial nose.

\section{Discussion}

The results obtained when testing the thermistor and the thermocouple showed a considerable nonlinear relationship between $V^{\prime}$ th and the actual $V^{\prime}$ (fig. 3). The depen-dence of the thermistor response on the airflow pattern (amplitude, waveform and frequency (fig. 4)), on the distance from the thermistor to nose and on the section of the nostrils (fig. 5) indicates that it is not possible to reliably quantify airflow with these thermally sensitive devices in sleep studies. Owing to the observed nonlinearity, the main consequence of using the amplitude reduction in thermistor/thermocouple signals to score hypopnoeas would be a considerable underdetection of these respiratory events. According to the curvilinear relationship between $V^{\prime}$ th and $V^{\prime}$ (figs. 3-5), a flow with small amplitude is overestimated when compared with a flow with a greater amplitude. Consequently, a reduction in airflow as in the case of hypopnoeas is systematically underdetected (fig. 2). The difficulty of accurately quantifying flow reduction during hypopnoeas in sleep studies is enhanced 
by the fact that the nonlinear relationship $V^{\prime}$ th- $V^{\prime}$ depends on the frequency and on the waveform of the breathing flow. This may particularly affect the detection of obstructive hypopnoeas, since in this case the inspiratory flow tends to change from a quasisinusoidal (normal breathing) to an almost square-wave pattern [11], which, according to figure 4, tends to further underestimate hypopnoeas. As illustrated in the example in figure 2 (left and right), change from a sinusoidal pattern to a square-wave flow of $50 \%$ amplitude results in a change of only $5 \%$ in thermistor signal.

The laboratory model allowed us to reproduce the conditions of assessing the breathing flow with thermistors or thermocouples. When compared with testing thermistor/ thermocouples in subjects $[5,7,8]$, this model has the advantage of allowing us to define controlled flow conditions for selectively analysing the different factors that influence the response of the thermal probes. The thermally sensitive device was subjected to the airflow pattern generated by the linear motor in such a way that the inspiratory airflow was at room temperature $\left(22^{\circ} \mathrm{C}\right)$ and the expiratory flow was at $37^{\circ} \mathrm{C}$. The air in the chamber was not saturated with water vapour since the effect of condensed water in commercial thermistors was shown to be small [5]. The thermistor/thermocouple was exposed to realistic flow amplitudes ranging from values typical of normal breathing $\left( \pm 0.8 \mathrm{~L} \cdot \mathrm{s}^{-1}\right)$ to those of severe hypopnoeas $\left( \pm 0.05 \mathrm{~L} \cdot \mathrm{s}^{-1}\right)$ and for frequencies $(10,15$ and 20 $\mathrm{bpm}$ ) within the range of observed respiratory frequencies. Moreover, we tested two different airflow waveforms (sinusoidal and square-wave) to assess the response of the thermistor when subjected to changes of breathing pattern such as those found in patients from normal breathing to the typically flow-limited airflow during obstructive hypopnoeas [11].

The limitation of thermistor/thermocouples for reliably quantifying airflow to detect hypopnoeas in sleep studies is due to the fact that the signal provided by these devices is directly related to the temperature of the sensing element and only indirectly related to the airflow. Indeed, the $V^{\prime}$ th is a measure of the temperature-dependent resistance (thermistor) or the electromotive force (thermocouple) in the probes. The sensor temperature varies because the probe is surrounded by inspiratory and expiratory flows with a variable temperature. The change in the thermistor/thermocouple temperature is the result of a convective heat transfer in which breathing airflow and sensor temperature are related by a nonlinear differential equation [6]. The fact that we found virtually the same results for the thermistor as for the thermocouple (fig. 3) indicates that air convection around the thermally sensitive devices is the most influential factor in this application. Therefore, it is expected that different models of thermistors/thermocouples would exhibit the same kind of nonlinear behaviour shown in figure 3. Airflow convection also accounts for the changes in the relationship $V^{\prime}$ th- $V^{\prime}$ found in figure 5 when increasing the section of nares or the distance between the thermistor and the nose. According to this figure, the relationship $V^{\prime}$ th- $V^{\prime}$ tended to be less nonlinear as the thermistor approached the nostrils. Owing to the nonlinear equations characterizing the heat transfer in the thermistor/thermocouple and to the dep-endence of the sensor response on the air waveform, it is not possible to perform a dynamic correction of the rec-orded signal, as in the case of linear flow transducers. In-deed, the thermally sensitive device is not well described by an input-output frequency response function. Consequently, dynamic parameters such as the time-constant of thermal interchange, which are useful in characterizing linear thermometers, are meaningless when assessing bre-athing flow to detect hypopnoeas. This contrasts with the behaviour of the nasal prongs, which are simple devices recently proposed for monitoring airflow in sleep studies [12]. As nasal prongs exhibit a memory less nonlinearity and an excellent time-response, the signal obtained can be easily corrected to linearize the flowmeasuring system.

In conclusion, the dynamic response of thermistor/ thermocouples was characterized under controlled laboratory conditions with a model simulating the breathing airflow. The signal from these thermally sensitive devices was nonlinearly related to the actual flow measured with a reference pneumotachograph. Owing to their poor time response and to the influence of the airflow pattern and of the geometrical constraints, thermistor/thermocouples are unable to accurately measure airflow. The use of the reduction in the thermistor/thermocouple signal to quantify hypopnoeas in sleep studies may result in considerable underdetection of these respiratory events.

Acknowledgement: The authors wish to thank M.A. Rodríguez for his technical assistance.

\section{References}

1. American Thoracic Society. Indications and standards for cardiopulmonary sleep studies. Am J Respir Crit Care Med 1989; 139: 559-568.

2. Levy P, Pepin JL, Wuyam B, Veale D. Respiratory monitoring in sleep apnea syndrome. Sleep 1992; 15: S5-S8.

3. Stradling JR. Sleep studies for sleep-related breathing disorders. J Sleep Res 1992; 1: 265-273.

4. Doebelin EO. Measurement systems, application and design. 4th Edn. New York, McGraw-Hill, 1990; pp. 692-706.

5. Xiong C, Sjöberg BJ, Sveider P, Ask P, Loyd D, Wranne B. Problems in timing of respiration with the nasal thermistor technique. J Am Echocardiogr 1993; 6: 210-216.

6. Stork K, Karlsson M, Ask P. Heat transfer evaluation of the nasal thermistor technique. IEEE Trans Biomed Eng 1996; 43: 1187-1191.

7. Pastó M, Felez MA, Gea J, et al. The efficiency of thermocouple in measuring hypopneas. Eur Respir J 1995; 8 (Suppl. 19): 253S.

8. Pastó M, Felez MA, Romero A, Gea J, Orozco-Levi M, Broquetas JM. Comparison between thermocouple and inductance plethysmography to detect hypopneas. Eur Respir J 1996; 9 (Suppl. 23): 196S.

9. Navajas D, Farré R. Respiratory input impedance during high frequency oscillatory ventilation. Br J Anaesth 1989; 63: 85S-90S.

10. Farré R, Rotger M, Montserrat JM, Navajas D. A system to generate simultaneous forced oscillation and continuous positive airway pressure. Eur Respir J 1997; 10: 1349-1353.

11. Montserrat JM, Ballester E, Olivi H, et al. Time-course of stepwise CPAP titration: behavior of respiratory and neurological variables. Am J Respir Crit Care Med 1995; 152: 1854-1859.

12. Montserrat JM, Farré R, Ballester E, Felez A, Pastó M, Navajas D. Evaluation of nasal prongs for estimating nasal flow. Am J Respir Crit Care Med 1997; 155: 211-215. 